\title{
O equívoco no discurso da inclusão: o funcionamento do conceito de diferença no depoimento de agentes educacionais ${ }^{1}$
}

The mistake in the inclusive discourse: the functioning of the concept of difference within the educational agents' statements

Juliana Santana Cavallari*

Universidade de Taubaté

RESUMO: Este estudo se propõe a analisar o modo como o discurso da inclusão produz efeitos de verdade em nosso meio sócio-histórico, ao evocar outros domínios discursivos. Ancorada na perspectiva discursiva, perpassada pela psicanálise lacaniana, foram destacadas algumas regularidades nos depoimentos proferidos por agentes educacionais, durante palestras realizadas em um congresso sobre "inclusão e diversidade". Partindo da questão: como os conceitos de inclusão e diferença colocam os dizeres de agentes educacionais em funcionamento?, a análise do corpus discursivo evidenciou a aparente "necessidade" de aplicação do discurso da inclusão como eliminador das diferenças (físicas ou não), o que, imaginariamente, possibilitaria uma prática pedagógica mais justa e igualitária. Trata-se, portanto, de um equívoco de ordem ideológica, tendo em vista que a prática discursiva em questão não visa a incluir as diferenças ou tratá-las de modo singular, mas a criar identidades fixas, conservadoras e repetitivas.

PALAVRAS-CHAVE: educação inclusiva; práticas discursivas; equívoco; agentes educacionais.

ABSTRACT: The purpose of this study is to analyze the way the discourse upon inclusive practices produces some effects of truth within our social and historical environment, by evoking other discursive domains. Through a discursive perspective, affected by the psychoanalysis, some regularities enunciated by educational agents, during speeches given at a Congress concerning inclusion and diversity, were pointed out. The analysis of the data was based on the following question: to what extent the concepts of difference and inclusion make the talk of educational agents meaningful? The results have stressed the "necessity" felt by the educational agents of applying the inclusive discourse to promote a fair and

\footnotetext{
${ }^{1}$ A versão inicial deste estudo foi apresentada no VI Congresso Internacional da ABRALIN. * judu77@hotmail.com
} 
equal pedagogical practice. Taking into account that this kind of practice tends not to treat the differences in a singular way, it's possible to state that repetitive, traditional and permanent identities have been built within the educational context, regardless the new educational purposes.

KEYWORDS: inclusive education; discursive practices; mistake; educational agents.

\section{Introdução}

$\mathrm{Na}$ tentativa de promover a democratização da escola e do ensino, tal como nos aponta o estudo de Vizim (2003), uma série de ações políticas foi adotada pelo governo, sobretudo a partir da década de 1990. Com a Declaração da Educação para Todos (1990), a Política Nacional de Educação Especial (1994), dentre outras propostas, buscou-se, por meio da adoção de práticas inclusivas, atender às necessidades dos excluídos, isto é, daqueles que sofrem algum tipo de privação social ou deficiência física. Assim sendo, o discurso político-educacional, difundido não só por governantes ou representantes legais, mas, em especial, por agentes educacionais, tende a reforçar e a assegurar a aplicação de práticas inclusivas, o que, imaginariamente, possibilitaria um processo de ensino e aprendizagem mais justo e igualitário.

Partindo do seguinte questionamento: como os conceitos de inclusão e diferença (con)formam e engendram o dizer-fazer de agentes educacionais?, o objetivo específico deste estudo é desvelar o modo como intra e interdiscursivamente o discurso da inclusão ou a prática de educação inclusiva - tida como política e moralmente correta - produz efeitos de sentido e de verdade em nosso meio sócio-histórico. Com base no pressuposto de que a prática e política inclusivas evocam conceitos que significam se pensados em pares dicotômicos (inclusão x exclusão) e que já se encontram naturalizados no contexto escolar, a hipótese levantada neste estudo é a de que a educação inclusiva (EI) silencia a(s) diferença(s) e o diferente, já que incluir passa a ser significante de normalizar ou de tornar o outro meu semelhante.

Como material de pesquisa foram utilizados alguns depoimentos proferidos por agentes educacionais (professores, assistentes, coordenadores de cursos, diretores, pedagogos e psicólogos), por ocasião de algumas palestras e seminários realizados em um congresso nacional cujo tema era "inclusão e diversidade”. O evento em questão aconteceu no segundo semestre de 2008.

Do ponto de vista teórico, os pressupostos da Análise do Discurso de linha francesa $(\mathrm{ADF})$ - em especial a última fase dos estudos pêcheutianos, já 
afetados pela 'descoberta' do inconsciente - fundamentam as análises empreendidas e as consideraçóes propostas ao término deste artigo.

Em última instância, o estudo em questão sugere o acolhimento das diferenças e da ingovernabilidade que, vez por outra, irrompem no espaço de sala de aula, de modo que possamos atuar como agentes educacionais, no sentido de não temermos ou ficarmos passivos diante do inesperado, mas de concebermos a diferença e o diferente como fatores produtivos que provocam transformações e, portanto, deslocam saberes pré-construídos ou normalizados sócio-historicamente.

A seguir, abordarei o conceito de equívoco que perpassa a análise dos dados.

\section{O equívoco na produção de sentidos outros}

Tendo em vista a problemática levantada neste estudo "o equívoco no discurso da inclusão", faz-se necessário adentrarmos o conceito de equívoco que viabilizou o recorte efetuado no material de análise.

De acordo com a abordagem discursiva, o equívoco 'desnuda' a verdade do sujeito que enuncia, ao produzir uma falha material que foge ao seu controle. Essa falha materializada na/pela língua não pode ser recoberta, possibilitando a produção de sentidos outros, por vezes indesejáveis e que denunciam a posição ocupada pelo sujeito de linguagem, bem como as formaçōes discursivas em que seu dizer se inscreve para produzir determinados sentidos. Nesse prisma, não é o sujeito que fala a língua, mas, sim, a língua que fala a verdade do sujeito, uma vez que aponta para as suas formaçôes ideológicas e para os vários discursos que legitimam seu dizer.

Essa noção de equívoco ou de equivocidade que suporta o duplo, o heterogêneo ou ainda tudo aquilo que ultrapassa a vontade do sujeito enunciador também se faz presente na psicanálise. Em ambas as perspectivas teóricas, a verdade não se apresenta na aparente unidade discursiva, mas se dá a escutar por meio de formaçōes do inconsciente ou da equivocidade que é própria da linguagem. Nas palavras de Lacan (1975 [1986, p. 302]),, "nossas palavras que tropeçam são as palavras que confessam. Elas revelam uma verdade de detrás".

\footnotetext{
${ }^{2}$ Quando houver duas datas, a primeira corresponde à edição original da obra; a segunda, à edição consultada.
} 
Com base nas considerações arroladas é possível afirmar que, estruturalmente, todo e qualquer dizer é tomado pelo equívoco ou pela possibilidade de deriva de sentidos, uma vez que o sujeito de linguagem é duplamente marcado: pela ideologia e pelo inconsciente. Ao encontro de tais afirmações, Mariani (2006) postula que o equívoco se instaura nos sentidos produzidos por um determinado acontecimento discursivo, à revelia do sujeito enunciador, e faz falhar a vontade de unidade e transparência da comunicação, pois incorpora o real em suas análises do simbólico e do imaginário. São justamente esses pontos de equívoco ou de deslize de sentidos, que se dão a escutar na materialidade posta, que serão resgatados na análise dos acontecimentos discursivos, de modo a melhor compreender como a prática inclusiva significa no contexto escolar.

\section{Procedimentos metodológicos}

Como já mencionado anteriormente, lançaremos um olhar discursivo ao corpus, para entendê-lo não como conteúdo ou testemunho de verdade, mas para abordar, nos enunciados analisados, a formação discursiva em que o sujeito de linguagem se inscreve, para que suas palavras tenham sentido (ORLANDI, 1996). Em suma, a abordagem discursiva ancora a análise dos registros na materialidade linguística, 'desnudando' os aspectos sócio-históricoideológicos que atuam na constituição dos sentidos e que são 'esquecidos' pelo sujeito que enuncia.

Vale salientar ainda de que forma os pressupostos da ADF e da psicanálise dialogam entre si, orientando os procedimentos analíticos realizados no material de pesquisa. Para a ADF, o funcionamento discursivo é engendrado pela articulação entre a ideologia e as condições de produção do discurso, isto é, o contexto sócio-histórico de sua enunciação e o lugar discursivo ocupado pelo falante. Na teoria psicanalítica, por sua vez, a determinação dos sujeitos e dos sentidos é inconsciente e atemporal e só se faz acessível por meio da linguagem que comporta falhas ou buracos. Feitas essas colocações, postulase uma relação da ideologia com o inconsciente, por meio da linguagem, ou seja, a ideologia, assim como o inconsciente, embora oculta ao sujeito enunciador, se mostra no funcionamento do discurso: da estrutura ao acontecimento. Pêcheux (1983 [1997]) reflete sobre a materialidade da linguagem como região de equívoco em que se ligam materialmente o inconsciente e a ideologia. Dito de outro modo, o sujeito da estrutura é afetado pela determinação inconsciente que possibilita que as redes de 
memória e as formações ideológicas, às quais o discurso e o sujeito se filiam para produzir sentidos, escapem ao saber do eu. Observa-se, portanto, que o funcionamento da ideologia não constitui um saber consciente, embora seja condição de existência do sujeito e do discurso, uma vez que governa o fazer-dizer.

Nas análises que se seguem, serão destacadas algumas regularidades que constituem equívocos de ordem ideológica e que, em função dos sentidos que produzem, para além do saber consciente do enunciador, apontam para a posição discursiva e ideológica adotada em relação à proposta de educação inclusiva.

Convém retomar que os excertos analisados foram coletados em um congresso nacional, sediado em uma instituição particular de ensino superior do Vale do Paraíba, cuja proposta era discutir questôes acerca da inclusão e diversidade. Durante a realização de algumas palestras e seminários, agentes educacionais que exercem funções distintas no contexto escolar como: professores, representantes do MEC, diretores, pedagogos, dentre outros, formularam algumas considerações sobre o referido tema. Algumas dessas formulações foram transcritas pelo pesquisador e posteriormente selecionadas para este estudo, a fim de elucidar alguns questionamentos propostos.

\section{Análise dos dados}

De modo a elucidar a questão de pesquisa que direciona a análise dos dados (como os conceitos de inclusão e diferença (con)formam e engendram o dizer-fazer de agentes educacionais?), faz-se necessário rastrearmos a presença do interdiscurso que interpela e legitima os depoimentos proferidos pelos sujeitos pesquisados. Vale ressaltar que não se trata de individualizar ou responsabilizar o sujeito enunciador por suas supostas falhas ou equívoco, mas de compreendermos como as práticas discursivas provocam efeitos de verdade. Passemos à análise do corpus.

Por ocasião da palestra de abertura, o reitor da universidade onde o evento foi sediado proferiu:

[E1] Incluir na pauta um congresso de inclusão e diversidade visa a resolver melhor esta situação no Brasil. De mãos dadas pretendemos caminhar neste tema com a participação efetiva da universidade. A inclusão é abrangente e parece imposta. Podemos dar uma contribuição social, ao propor o desmonte de mecanismos de exclusão. 
Com base no excerto acima, observa-se que o sujeito de linguagem inicia sua fala reiterando a necessidade de promover a inclusão "com a participação efetiva da universidade". A materialidade posta põe em evidência a função social que a escola e seus agentes devem exercer e que parece se sobrepor à função de ensinar ou de construir saberes. Mais especificamente, a função social exercida pela universidade e seus representantes passou a ser a de normalizar e hospedar - por vezes hostilizar - o diferente, sem, de fato, incluí-lo de modo significativo, tendo em vista que aos normais ou aos profissionais que têm seu saber cientifica e socialmente legitimado é dado o direito de construir saberes sobre os que são representados e marcados como anormais. Ferre (2001) já havia salientado a contradição inerente ao saber produzido na/pela universidade, via práticas discursivo-pedagógicas. Nas palavras da autora (op.cit., p.199),

[o] que na Universidade se produz pode ser tudo ao contrário: nenhuma reflexão sobre um sujeito próprio, nenhum saber ou sabor acerca de nossa intimidade e um acúmulo de conteúdos sobre o outro que o define, o identifica e o encerra em um opaco envoltório tecnicista que faz dos demais os especiais, os descapacitados, os diferentes, os estranhos, os diversos e de nós os obviamente normais, os capacitados, os nativos, os iguais; e, por isso, dois são os tipos de identidade que a Universidade segue produzindo ao transmitir o conhecimento acadêmico, científico e técnico que alude à diferença e à diversidade na educação: a identidade normal e a identidade anormal; é a esta segunda a que se passou a chamar de diferente, especial ou diversa.

A repetição redundante do termo incluir, que no excerto em questão é pronunciado três vezes, sem que haja o questionamento incluir o quê, quem e como? sugere a naturalização de verdades hegemônicas que se materializam no discurso político-educacional, ao representar, discursivamente, a proposta de educação inclusiva como um compromisso de todos ou, segundo o enunciador, como um meio de "dar uma contribuição social e de resolver melhor esta situação no Brasil". Além disso, na formulação em questão, o sujeito de linguagem deixa escapar que a situação da inclusão ainda não se resolveu no Brasil, tendo em vista que o que já está resolvido não requer melhoras ou futuras soluçóes.

O uso da primeira pessoa do plural, no trecho: "de mãos dadas pretendemos caminhar neste tema; podemos dar uma contribuição social", provoca um efeito de convocação e de participação de todos os agentes educacionais, de modo a viabilizar a inclusão que ainda parece não ter sido 
alcançada, já que se trata ainda de um "tema" a ser discutido em um congresso da área. Esse efeito de convocação é produzido pelo discurso progressista e da união social que versa sobre a união de todos como forma de se atingir o progresso e a ordem.

Embora o sujeito pesquisado proponha "o desmonte de mecanismos de exclusão", deixando entrever uma certa noção dos mecanismos de poder engendrados pela ideologia hegemônica, o enunciador parece não se dar conta de que a viabilização da inclusão no contexto escolar não depende única e exclusivamente da "boa" vontade dos agentes educacionais ou de seu poder transformador, uma vez que os tais mecanismos de exclusão, bem como o modelo de escola excludente que ainda é predominante em nosso meio, foram legitimados ao longo de uma trajetória político-econômica que, por meio de práticas discursivas e de jogos de poder-saber, tal como nos aponta a visão foucaultiana, foram construindo verdades sobre os excluídos e sobre a necessidade de incluí-los. Ao longo dos anos, a insignificância e a (in)fâmia ${ }^{3}$ daqueles que foram discursivamente marcados como excluídos parece ganhar certa importância e vira alvo das instituiçôes 'normalizadoras', no caso: a escola, já que a exclusão e os excluídos passam a ameaçar a acomodação social e a cidadania.

Ainda em relação ao excerto anterior [E1], apesar de tentar modalizar o seu dizer sobre a proposta da inclusão, ao formular "a inclusão é abrangente e parece imposta", o equívoco que produz sentidos 'indesejados' também marca a posição discursiva, portanto ideológica, que o sujeito assume em relação ao tema abordado. O caráter impositivo da educação inclusiva se materializa na formulação em questão, apontado para o fato de que a inclusão é bastante complexa e não é um procedimento natural, pois, se assim o fosse, não precisaria ser apresentada na forma de lei ou de proposta pedagógica a ser seguida. Nesse prisma, é significativo ressaltar que a natureza humana é mais seletiva do que inclusiva, uma vez que, segundo Skliar (2006), a diferença tende a ser vista negativamente, já que aponta para o intolerável ou para fora da normalidade. Ao encontro dessas idéias, Ferre (2001, p. 197) enfatiza que o mundo dos ditos 'normais' é um mundo onde "a presença de seres diferentes aos demais, diferentes a esses demais caracterizados pelo espelhismo da

\footnotetext{
${ }^{3}$ Segundo Foucault (1992, p. 90), os (in)fames não são apenas os personagens de nossa história que cometem algum ato vil, mas, sobretudo, aqueles "cuja existência foi ao mesmo tempo obscura e desafortunada”.
} 
normalidade, é vivida como uma grande perturbação”.

A menção ao caráter impositivo da educação que prega a inclusão de todos, em especial das pessoas que possuem algum tipo de deficiência física, marcada no corpo, também foi observada no excerto a seguir, formulado por uma diretora de uma escola pública de ensino fundamental:

[E2] A inclusão é um susto, um espanto. Ela chegou de repente e a gente tem que saber o que fazer. Na verdade, ela está entre nós desde 71, com a lei 5.692/71.

No excerto em questão, o enunciador deixa escapar seu espanto diante da proposta da inclusão, apesar de enunciar a partir do lugar de dirigente de uma instituição escolar que, em conformidade com as leis vigentes, deveria garantir a política e educação inclusivas. Ao se dar conta do equívoco de ordem ideológica que seu dizer produziu, o enunciador faz alusão à lei que garante a aplicação de práticas inclusivas, por mais espantosas ou assustadoras que possam parecer. Assim sendo, apesar de toda insegurança vivenciada pelos agentes educacionais diante do estranho e do diferente que, na maioria das vezes, vira sinônimo de deficiente, a necessidade de tudo saber e de fornecer respostas acertadas para situações inesperadas constitui a identidade do sujeito em questão, além de governar seu fazer pedagógico, tal como sugere a formulação: "a gente tem que saber o que fazer".

A formulação posta acima parece dialogar com o próximo excerto, formulado por uma pedagoga que, no evento em questão, representava o MEC e suas propostas:

[E3] A dona inclusão não está só batendo na porta, ela está dentro da sala de aula. A postura do MEC é essa: todos na sala de aula e ai a gente vai caprichando na qualidade.

A formulação "a postura do MEC é essa: todos na sala de aula e aí a gente vai caprichando na qualidade" reflete as políticas públicas brasileiras que se caracterizam pelo improviso e despreparo dos profissionais envolvidos, no caso: dos agentes educacionais que, mesmo sem a capacitação ou instrução necessária para trabalhar com o aluno especial, devem acolhê-lo no espaço de sala de aula, ainda que isso implique na má qualidade da educação oferecida. Como já sugerido por Coracini (2007, p.107), o fato de partilhar do mesmo espaço físico não significa "por si só e por força da lei, ausência de discriminação, in-clusão, in-serção social". Posteriormente, a autora (op.cit., p. 109) conclui que "a vontade de igualar, de homogeneizar na melhor das intenções (...) é que 
cava um abismo ainda maior entre uns e outros”, isto é, entre os alunos 'ditos' normais e os representados como excluídos ou especiais. Assim sendo, a própria escola que se diz inclusiva, acaba construindo muros que segregam a diferença e excluem ainda mais.

Partindo da premissa de que todos são iguais ou ainda de que a igualdade é um ideal a ser alcançado, a educação inclusiva silencia as diferenças que poderiam provocar transformações produtivas no contexto escolar. Em nome de uma prática pedagógica mais justa e igualitária, igualam-se, também, os sujeitos e seus desejos, confinando-os a um mesmo espaço e práticas. Esta noção de que todos são iguais ou de que devem ser iguais ganha sentidos a partir da ideologia religiosa e jurídica, segundo as quais os homens são iguais perante Deus e perante a lei. Nesse prisma, a aplicabilidade da lei ou, no caso, da educação inclusiva assegura os direitos de todos, ganhando estatuto de compromisso moral e social.

No excerto anterior, diversos efeitos de sentidos são produzidos, a partir da personificação da 'inclusão', na seguinte formulação: “a dona inclusão não está só batendo na porta, ela está dentro da sala de aula”. O sujeito de linguagem sugere que a inclusão já está sendo contemplada pelo simples fato de permitir que o aluno diferente e/ou deficiente permaneça no mesmo espaço dos alunos 'normais'. Em outras palavras, a inclusão se personifica na figura do aluno diferente, muitas vezes confundido e entendido como deficiente, e parece perder o caráter de proposta transformadora e significativa que deveria dar subsídios à prática pedagógica. Tendo em mente a questão da hospitalidade, tratada por Derrida (2003), é possível afirmar que aos agentes educacionais, em especial ao professor, é dada a difícil tarefa de hospedar e ser hospitaleiro, isto é, não hostil, com esse estranho que foi inserido - mas não totalmente incluído - no espaço de sala de aula da escola regular, na ilusão de ser possível se atingir e viabilizar uma hospitalidade universal: "sem reservas, sem limites, sem fronteiras" (CORACINI, 2007, p. 110).

Propondo um alinhavo entre a leitura de Lacan (1962-1963), a temática aqui abordada e a materialidade destacada anteriormente, observa-se que $a$ inclusão do diferente é representada como uma visita inesperada ou como um hóspede desconhecido que "bate na porta" e aparece inopinadamente, adentrando e ameaçando a estabilidade de um mundo já normalizado, com fronteiras bem demarcadas. Nas palavras de Lacan (op.cit., p. 87), " esse hóspede é o que já passou para o hostil [hostile] (...). No sentido corriqueiro, esse hóspede não é heimlich, não é o habitante da casa, é o hostil lisonjeado, 
apaziguado, aceito". É justamente esta posição de hostil aceito e lisonjeado que é assumida pelo aluno diferente e/ou deficiente, na escola regular, tendo em vista que tal aceitação está prevista em lei, além de tornar os agentes educacionais mais tolerantes e generosos, em conformidade com a ideologia e discursividade religiosa.

$\mathrm{O}$ último excerto abordado neste estudo foi formulado por uma professora de ensino fundamental e médio da rede pública, que trabalha com alunos especiais em turmas regulares. O equívoco que possibilita a deriva de sentidos indesejados também se fez presente na materialidade posta. Vejamos:

[E4] Temos que resgatar um erro. Tratamos as pessoas diferente porque elas são diferente de nós [sic]. Nós é que excluímos as pessoas. Temos que deixar de fixar a imagem nos estereótipos.

O esquecimento 2, de ordem da enunciação, segundo Pêcheux (1975 [1988]), provoca diferentes efeitos de sentido na referida formulação. Em outras palavras, ao empregar o verbo resgatar, em vez de corrigir, o sujeito de linguagem nos permite entrever sua posição discursiva, portanto, ideológica, segundo a qual o aluno diferente ou deficiente é visto como um erro que deve ser resgatado ou corrigido por nós, "os normais", que temos o poder de construir um saber sobre o outro.

Nos depoimentos dos agentes educacionais, de um modo geral, os conceitos de diferente e deficiente se confundem, justificando a necessidade da aplicação de práticas pedagógicas igualitárias e simplificadoras das diferenças. Lembrando que a inclusão se faz necessária para além das deficiências, podemos afirmar que um equívoco de ordem ideológica está em funcionamento nos depoimentos abordados e na proposta de EI, conforme propõe Vizim (2003, p.52), na citação abaixo:

[o] tema educação inclusiva, apontado na década de 1990, ficou restrito, por vezes, à educação de pessoas com deficiências. Cabe ressaltar que esta é uma situação lamentável diante da complexidade de se criar uma política pública de educação para todos. Não se trata única e exclusivamente do segmento das pessoas com deficiência, no sentido de incluí-los nas escolas regulares, deve-se incluir também toda criança, jovem e adulto que vive a condição de analfabeto ou de analfabeto funcional, de diferença étnica, cultural, religiosa, de condição social, enfim, de marginalização diante da hegemonia social.

Em uma formulação do excerto anterior: "Tratamos as pessoas diferente porque elas são diferente de nós [sic]", nota-se uma fala pouco significativa, 
circular e esvaziada de sentidos, uma vez que apenas evoca discursos e conceitos já naturalizados em nosso contexto sócio-histórico. Esse esvaziamento de sentidos também foi abordado por Coracini (2007), com base na análise de depoimentos de professores. Nas palavras da autora (op.cit, p. 101-2), "o que se percebe é uma repetição redundante de termos que parecem esvaziados de sentidos ou tão pelos de sentido - naturalizado pela ideologia dominante que não precisam de explicitação (...)". Nesse prisma, pode-se considerar que a naturalização é desastrosa e infértil, já que não promove transformações e/ ou deslocamentos.

Ainda em relação ao excerto anterior, nota-se que o sujeito de linguagem convoca os agentes educacionais para o seu dizer, ao fazer uso da primeira pessoa do plural (nós, temos) e atribuir a eles e a si mesmo a culpa pela exclusão praticada no contexto escolar "nós é que excluímos as pessoas". Na formulação em questão, ocorre a individualização e responsabilização do sujeito por seus atos e escolhas. O enunciador não se vê afetado por outros discursos que circulam em nosso meio e que produzem "verdades", mas como o único agente capaz de fazer escolhas acertadas, que possibilitem a inclusão. Segundo Kehl (2001, p.59), dentro dessa modalidade subjetiva moderna, leia-se: contemporânea, "o sujeito não se dá conta de suas filiações simbólicas e passa a se considerar como um indivíduo isolado". Daí surgem sentimentos diversos, como culpa e angústia, diante do insucesso da EI e suas propostas.

\section{Considerações finais}

Os dados analisados reforçam a hipótese de que a educação inclusiva (EI) silencia a(s) diferença(s) e o diferente, já que incluir passa a ser significante de normalizar ou de tornar o outro meu semelhante e sugerem que a prática e política inclusivas evocam conceitos que parecem significar, se pensados em pares dicotômicos como: exclusão x inclusão; diferença x igualdade, dentre outros. São esses conceitos e oposições, extremamente simplificadores e homogeneizantes, que incidem na constituição identitária do sujeito marcado e representado como excluído ou incluído, uma vez que constituem as imagens sobre si mesmo. Segundo Souza (1995), as práticas discursivas e os conceitos que as fundamentam são tratados de forma unívoca: sem equívocos, falhas ou enganos. Assim sendo, a prática pedagógica, direcionada pelo discurso políticoeducacional que reforça a proposta de EI, pautada na busca de igualdade, tende a criar identidades narcísicas. 
A materialidade posta também possibilitou a problematização do modo como o discurso da inclusão e as práticas "ditas" inclusivas concebem a diferença e a singularidade que são constitutivas da identidade de todo e qualquer sujeito de linguagem e não apenas daqueles que têm a diferença marcada no corpo. Skliar (2006, p.29) reforça que "acabamos reduzindo toda alteridade a uma alteridade próxima, a alguma coisa que tem de ser obrigatoriamente parecida a nós - ou ao menos previsível, pensável, assimilável". Em um estudo anterior (CAVALLARI, 2008, p.5), já havia apontado que a resistência em acolher as diferenças reside no fato de que tudo o que nos parece estranho ou não familiar expõe o não saber ou o não controle, desestabilizando o lugar de sujeito-suposto-saber que é constitutivo da identidade de agentes educacionais. Essa redução do estranho em familiar, do diferente em normal inviabiliza uma prática inclusiva significativa que contemple a singularidade do sujeito-aluno.

Um equívoco de ordem ideológica, bastante recorrente nos excertos abordados, deriva ainda da confluência de sentidos entre diferente e deficiente, resultante da igualação entre educação regular e educação especial que, por sua vez, é garantida pela proposta de EI.

Recorrendo aos personagens (in)fames da história e salientando a importância de resistir e confrontar o poder hegemônico, Foucault (1992, p.98) enfatiza a necessidade de "transpor os limites, de passar para o outro lado, escutar e fazer ouvir a linguagem que vem de fora ou de baixo (...). Estas vidas, por que não ir escutá-las lá onde falam por si próprias?" Transpondo tal questionamento para a prática inclusiva, conclui-se que os mecanismos de poder-saber, engendrados pelo discurso universitário que, segundo Lacan (1968-1969), formaliza e legitima o modo de se organizar as relações interpessoias, devem ser desconstruídos ou desnaturalizados, de modo a promover uma inclusão que acolha as diferenças e as especificidades de todo e qualquer sujeito de linguagem e não apenas daqueles ditos ou representados como anormais. Ao encontro de tais consideraçôes, Skliar (2003) propõe uma "pedagogia do acontecimento" que acolha o estranho, o diferente e o inesperado, sem temê-los ou silenciá-los, uma vez que são considerados como características produtivas dentro do processo de ensino e aprendizagem. Em última instância, sugiro que os conceitos de inclusão e diferença, já naturalizados no contexto escolar e no discurso político-educacional, sejam (re)pensados e (re)significados no interior de nossas experiências educacionais, para que, de fato, promovam transformações e desloquem o saber institucionalizado e historicamente determinado sobre o outro. 


\section{Referências}

CAVALLARI, J.S. O discurso da inclusão na eliminação das diferenças constitutivas do sujeito-aluno de línguas. In: SEMINÁRIO DE PESQUISAS EM LINGUÍSTICA APLICADA (SEPLA), 2008, Taubaté. Anais... Taubaté: UNITAU, 2008. p.1-6.

CORACINI, M.J. Identidade e cidadania: a questão da inclusão. In: CORACINI, M.J. A celebração do Outro: arquivo, memória e identidade: línguas (materna e estrangeira), plurilinguismo e tradução. Campinas: Mercado de Letras, 2007. p. 97-113.

DERRIDA, J. Da Hospitalidade. Trad. A. Romane. São Paulo: Escuta, 2003.

FERRE, N.P.L. Identidade, diferença e diversidade: manter viva a pergunta. In: LARROSA, J.; SKLIAR, C. Habitantes de Babel: políticas e poéticas da diferença. Belo Horizonte: Autêntica, 2001. p. 195-214.

FOUCAULT, M. A vida dos homens infames. In: $O$ que é um autor? Veja: Passagens, 1992. p. 89-128.

KEHL, M.R. Minha vida daria um romance. In: BARTUCCI, G. (Org.). Psicanálise, literatura estéticas de subjetivação. Rio de Janeiro: Imago Editora, 2001. p. 57-89.

LACAN, J. (1968-1969). O seminário 17: O avesso da psicanálise. Rio de Janeiro: Jorge Zahar, 1992.

LACAN, J. (1975). A verdade surge da equivocação. In: O Seminário Livro 1: Os escritos Técnicos de Freud. Trad. B. Milan. Rio de Janeiro: Jorge Zahar, 1986. p. 297-310.

LODI, A.C. A inclusão que é "nossa" e a diferença que é do "outro". In: RODRIGUES, D. (Org.). Inclusão e educação: dose olhares sobre a educação inclusiva. São Paulo: Summus, 2006. p. 15-34.

MARIANI, B. (Org.). A escrita e os escritos: reflexões em análise do discurso e psicanálise. São Carlos: Claraluz, 2006.

ORLANDI, E. P. Interpretação: autoria, leitura e efeitos do trabalho simbólico. Petrópolis: Vozes, 1996.

PÊCHEUX, M. (1983). O discurso: estrutura ou acontecimento. Trad. E. Orlandi. Campinas: Pontes, 1997.

PÊCHEUX, M. (1975). Semântica e discurso: uma crítica à afirmação do óbvio. Campinas: Editora da UNICAMP, 1988.

SKLIAR, C. A pergunta pelo outro da língua; a pergunta pelo mesmo da língua. In: LODI, A.C.; HARRISON, K.M.P.; CAMPOS, S.R.L.; TESKE, O. (Org.). Letramento e minorias. Porto Alegre: Meditação, 2003. Prefácio. 
SKLIAR, C. A inclusão que é "nossa" e a diferença que é do "outro". In: RODRIGUES, D. (Org.) Inclusão e educação: doze olhares sobre a educação inclusiva. São Paulo: Summus, 2006. p.16-34.

SOUZA, D.M. E o livro não "anda”, professor? In: CORACINI, M.J. (Org.). O jogo discursivo na aula de leitura: língua materna e língua estrangeira. Campinas: Pontes, 1995. p. 119-122.

VIZIM, M. Educação inclusiva: o avesso e o direito de uma mesma realidade. In: SILVA, S.; VIZIM, M. (Org.) Políticas públicas: educação, tecnologias e pessoas com deficiências. Campinas: Mercado de Letras: Associação de Leitura do Brasil (ALB), 2003. p. 49-71.

Recebido em dezembro de 2009. Aprovado em março de 2010. 